Quaestio facti. Revista Internacional sobre Razonamiento Probatorio Quaestio facti. International Journal on Evidential Legal Reasoning Seccion: Conjeturas y refutaciones N. 2 | 2021 pp. 299-311 Madrid, 2021 DOI: $10.33115 /$ udg_bib/qf.i2.22484 (C) Marcial Pons Ediciones Jurídicas y Sociales (C) Michael S. Pardo ISSN: 2604-6202

Recibido: 05/08/2020 | Aceptado: 12/08/2020 | Publicado: 20/01/2021 Editado bajo licencia Reconocimiento 4.0 Internacional de Creative Commons.

\title{
NATURALIZED EPISTEMOLOGY AND THE LAW OF EVIDENCE: METHODOLOGICAL REFLECTIONS
}

\author{
Michael S. Pardo \\ Professor of Law, \\ Georgetown University Law Center
}

ABSTRACT: This paper discusses Ronald Allen's article, "Naturalized Epistemology and the Law of Evidence Revisited", and reflects on how epistemology can contribute to our understanding of the evidentiary proof process. I first situate Allen's critique of recent philosophical scholarship, distinguishing between general theoretical accounts of proof (including the theory that Allen and I have defended), on one hand, and the applications of specific epistemological concepts or issues to law, on the other. I then present a methodological picture that diverges in some respects from the one that emerges from Allen's critique. In discussing this alternative methodological picture, I explain how epistemology can contribute to legal evidence and proof while avoiding the problems that Allen identifies.

KEYWORDS: Epistemology; legal proof; relative plausibility; statistical evidence; safety; sensitivity.

SUMMARY: 1. INTRODUCTION.-2. NATURALIZED EPISTEMOLOGY AND THE LAW OF EVIDENCE: THEN AND NOW.-3. AN ALTERNATIVE METHODOLOGICAL PICTURE.- 4. CONCLUSION.-5. BIBLIOGRAPHY.

RECOMMENDED CITATION: PARDO, MICHAEL S., 2020: «Naturalized Epistemology and the Law of Evidence: Methodological Reflections», in Quaestio facti, 2: 299-311. Madrid: Marcial Pons Ediciones Jurídicas y Sociales. DOI: http://dx.doi.org/10.33115/udg_bib/qf.i2.22484 


\section{INTRODUCTION}

Theoretical scholarship on legal evidence and proof has been on the rise throughout the world ${ }^{1}$. Roughly, and for purposes that will be clear in a moment, we can distinguish two different strands in the fabric of theoretical evidence scholarship. The first strand involves the application of theoretical concepts and insights from other academic disciplines. For example, within this strand, one might draw on developments in epistemology in order to apply some philosophical concept or insight to an issue in the legal domain ${ }^{2}$. A second strand of theoretical scholarship, also drawing on interdisciplinary resources, aims to provide a general theoretical account of the nature and structure of a legal system's evidentiary proof process as a whole and its component parts $^{3}$. A prominent example is the debate between probabilistic and explanatory accounts of proof and the ensuing shift from the former to the latter ${ }^{4}$. Although we can draw a rough distinction between these two stands, they are related. On one hand, specific epistemological considerations may provide support, or create problems, for general theoretical accounts 5 . On the other hand, operating within a general theoretical framework (and its attendant assumptions) may affect the plausibility of a particular application of epistemology to law and whether it successfully illuminates a legal issue ${ }^{6}$.

My purpose in drawing attention to these related but distinct strands of scholarship is to situate Ron Allen's article, "Naturalized Epistemology and the Law of Evidence Revisited", and my perspective in discussing it. I now find myself in the somewhat awkward position of being caught in an apparent tension between these two strands of scholarship. On one hand, Allen and I are the proponents of a general explanatory account of legal proof, known as relative plausibility ${ }^{7}$. On the other hand, my scholarship has also drawn on concepts and insights in epistemology in analyzing aspects of the evidentiary proof process, employing in the process some of the methodological aspects (e.g., "weird hypotheticals») that Allen powerfully critiques in his article. So, what gives?

In the discussion to follow, I will explain why I do not see a tension between these two strands of scholarship. I will also explain why I am more sanguine than Allen in the potential for epistemology to illuminate evidentiary issues in law. In focusing on these specific goals, my hope is that the discussion will help to elucidate more general

1 The existence of this journal, devoted to evidential legal reasoning, is further evidence of this rise. See, e.g., Pardo, 2018; Pardo, 2010; Pardo, 2007.

3 See, e.g., Pardo \& Allen, 2008; Allen \& Pardo, 2019a; Allen \& Pardo, 2019 b.

4 See the symposium on «Relative Plausibility and Its Critics», International Journal of Evidence \& Proof, 2019 (23): 1-217.

5 See, e.g., Goldman, 2002; LaUdan, 2008; НAack, 2014, each raising epistemological problems for subjective probabilistic accounts of legal evidence.

6 See PARDO, 2019, arguing that recent theoretical discussions of the "proof paradoxes» mistakenly assume a probabilistic account of standards of proof.

7 Pardo \& Allen, 2008; Allen \& Pardo, 2019a; Allen \& Pardo, $2019 \mathrm{~b}$. 
methodological issues and also to clarify possible ways in which epistemology can contribute to our understanding of evidence law, evidence theory, and legal proof. The next section provides some background and summarizes Allen's critique. Section 3 then provides and defends an alternative methodological picture, explaining how scholarship consistent with that picture can avoid the problems that Allen identifies.

\section{NATURALIZED EPISTEMOLOGY AND THE LAW OF EVIDENCE: THEN AND NOW}

Scholars exploring the relevance of «naturalized» epistemology for law have emphasized an instrumental connection between epistemic considerations and truth (or factual accuracy) ${ }^{8}$. The philosopher Alvin Goldman uses the term «veritistic» to refer to epistemic evaluation along this dimension ${ }^{9}$. According to Goldman, epistemic evaluation along this dimension examines the tendency of rules or practices to produce true beliefs or judgments (as opposed to errors or ignorance), and, accordingly, he argues that «it is natural to evaluate existing [legal] procedures along the verististic dimension» ${ }^{10}$.

In their 2001 article, «Naturalized Epistemology and the Law of Evidence», Ron Allen and Brian Leiter adopt Goldman's vertistic approach and argue that naturalized epistemology «provides the most appropriate theoretical framework for the study of evidence»" ${ }^{11}$. The veritistic approach on which they rely is "normative» and «regulative»— - it is concerned with the production of knowledge, meaning in part true belief» ${ }^{12}$. In assessing evidence law along this dimension, they emphasize two important constraints that epistemic evaluation «must honor» ${ }^{13}$. First, normative conclusions must respect the «ought implies can» constraint ${ }^{14}$. Second, epistemic

8 Goldman, 1999; Allen \& Leiter, 2001. On naturalized epistemology, see Quine, 1969; KorNBLith, 1994. On naturalism and legal theory, see LeIteR, 2017. «Naturalism» may refer to a variety of methodological or substantive claims; Allen's «naturalized» approach is primarily a methodological one. See Allen, 2020: 1-2 [citations are to manuscript pages].

9 Goldman, 1999: 69. Goldman is a pioneer in the branch of epistemology known as «social epistemology». See ALLEN \& Leiter, 2001: 1497 («Social epistemology is simply that branch of naturalized epistemology concerned not with individual knowers but with the social processes and practices that inculcate belief»).

10 Goldman, I999: 272. See also ibid:: 278 («The whole point of this chapter is to consider which systems or procedures of fact-finding are epistemically superior»). See also HaAcK, 2014; LaUdan, 2008.

11 AlLEN \& LeITER, 2001: 1493. In particular, their naturalized approach is one of applied social epistemology. Ibid:: 1497 («[N]aturalized social epistemology must consider the range of empirical sciences that examine the social mechanisms of belief-inculcation. In what follows, we shall often speak of "naturalized epistemology" and "social epistemology" interchangeably.»)

12 Ibid:: 1498 (original emphasis).

13 Ibid.: 1499.

14 Ibid. 
evaluations ought to be determined by instrumental considerations; they should be assessed according the "the actual consequences» of competing epistemic norms, evaluating "which are the most effective means of producing knowledge» ${ }^{15}$. With these methodological considerations in hand, Allen and Leiter examine theoretical approaches to legal proof as well as specific types of evidence and evidentiary rules ${ }^{16}$. In addition to their specific conclusions, the article is also useful methodologically, providing insightful examples of how to apply epistemology to the law of evidence.

In revisiting the relationship between naturalized epistemology and the law of evidence, Allen now applies some of the methodological considerations from that previous article to recent philosophical discussions of legal proof ${ }^{17}$. By «naturalized epistemology», Allen clarifies that he is primarily referring to «inquiries-analytical or empirical-into how the human mind engages with its environment and the implications of that form of engagement for Western legal systems» ${ }^{18}$. Examples of such inquiries include: «how such legal systems structure dispute resolution, the relationship between that structure and the field of evidence with its resultant rules, and how all of this is influenced by cognitive capacities» ${ }^{19}$. Allen's approach to investigating these issues follows the methodological constraints described above, including: the oughtimplies-can principle; a focus on «the actual state» of the legal system and its actors (informed by the best available empirical evidence); and a concern for the instrumental effects that any normative recommendations are likely to have on the legal system ${ }^{20}$.

In light of these methodological considerations, Allen first points to the success of «relative plausibility» as a general theoretical account ${ }^{21}$. This theory explains the evidentiary proof process, and its components, in terms of explanatory criteria and considerations ${ }^{22}$. After describing the success of relative plausibility, Allen critiques recent efforts by scholars relying on epistemology to provide "alternative», "competing explanations» of legal evidence and proof ${ }^{23}$. Unlike relative plausibility, these accounts «are at odds with an empirically oriented naturalized approach» and suffer from various «shortcomings» ${ }^{24}$. These «shortcoming» include: (1) the problem of the «weird

\footnotetext{
15 Ibid.

16 They discuss probabilistic and economic theories of evidence as well as specific rules concerning demeanor and character evidence. Ibid.: 1503-49.

17 Allen, 2020.

18 Ibid.: 2 .

19 Ibid.

20 Allen contrasts his methodology with «a priori, conceptual,» «a priori, top-down» and «conceptual/normative» analyses. Ibid.: 1, 4. As noted, however, his methodological approach includes within its scope both "empirical» and "analytical» inquiries. Ibid.

${ }_{21}$ The success of relative plausibility is contrasted with the failures of probabilistic theories. Ibid.: $4-10$.

22 Pardo \& Allen, 2008; Allen \& Pardo, 2019a; Allen \& Pardo, $2019 \mathrm{~b}$.

23 Ibid. 2-3. He discusses the Blue Bus and Gatecrasher hypotheticals and focuses the majority of his critique on recent philosophical discussions by ENOCH ET AL., 2012, and SMITH, 2018.

24 Ibid.: 1 .
} 
hypothetical»—《[h]ypotheticals are posited that are supposed to reflect some aspect of the legal system or the field of evidence, but do not» ${ }^{25}$; (2) «some theorizing neglects critical aspects of the actual state of affairs» ${ }^{26}$; and (3) «much of the theorizing [... makes essentially impossible epistemological demands ${ }^{27}$. Because of these problems, the alternative explanations are «implausible» and have little utility for law ${ }^{28}$.

I, of course, share Allen's views about relative plausibility. I also agree with many aspects of his general methodological discussion as well as many of his specific criticisms. Nevertheless, I remain more sanguine about the genre of scholarship that Allen critiques - in my view, epistemology may provide a greater source of understanding for legal evidence and proof than Allen's article may suggest ${ }^{29}$. In the next section, I will sketch an alternative picture.

\section{AN ALTERNATIVE METHODOLOGICAL PICTURE}

The methodological picture I will describe shares a number of details with the one that emerges from Allen's critique. In particular, there are five shared aspects that I take as a starting point:

First, and perhaps least controversially, theorizing about legal evidence and proof should accurately describe the object of inquiry. This is easier said than done when attempting to describe a complex entity such as the evidentiary proof process. But trying to avoid either misdescribing the object of inquiry or neglecting critical aspects of it are details of Allen's naturalized approach with which I assume no one would take issue.

Second, the ought-implies-can constraint is also one that, at least in principle, should be uncontroversial and, thus, I agree that theorizing should avoid making impossible demands, epistemological or otherwise.

25 Ibid.: 3.

26 Ibid.

27 Ibid.

28 Ibid: 1, 3, 6. It is important to note that although Allen is critical of some attempts to apply epistemology to law (i.e., what he calls the "cottage industry» focusing on statistical evidence, ibid.: 3), his argument is not a wholesale rejection of the relevance and significance of epistemology for evidence law. Indeed, both AlLen \& Leiter, 2001, and Allen's current paper (as well as some of our work on relative plausibility) involve applications of epistemological insights to law. There is no contradiction here. Allen's methodological approach, in my view, is thus best seen as charting a middle path between some types of epistemological applications, on one hand, and more extreme skeptical positions, on the other. For more extreme expressions of skepticism about the relevance of epistemology for evidence law, see PARK, 2001: 2067; ENOCH ET AL., 2012: 211 («[T] he law should not care about knowledge, or indeed about epistemology in general»).

29 For reasons discussed below, some of the possible differences between our methodological pictures are likely to be a matter of focus and framing, as opposed to genuine substantive disagreement. See ibid.: 14-15 n. 48. 
Third, the instrumental constraint, as outlined by Allen and Leiter, is an important one for social institutions such as law ${ }^{30}$.

Fourth, I share Allen's anti-reductionist impulse. No theory is likely to provide a «key» or an algorithm for understanding all aspects of legal proof based on a small subset of variables. This is true for probabilistic approaches to legal proof, and it is also true for theories that draw on additional epistemological concepts (e.g., knowledge, justification, warrant, safety, sensitivity, normic support, and so on).

Fifth, as mentioned, I share with Allen the view that our explanatory theory, relative plausibility, provides the best available general account of the evidentiary proof process. Thus, I envision work that draws on additional aspects of epistemology as being complementary to, rather than in competition with, relative plausibility ${ }^{31}$.

Thus, the alternative picture that I envision is empirically informed, anti-reductive, and consistent with the best general theoretical account of legal proof (relative plausibility). According to this picture, epistemic concepts and issues help to inform, clarify, and illuminate features of the evidentiary proof process. One theoretical upside of this methodological approach is that it may help to make explicit features or issues that are implicit in the evidentiary proof process. Elucidating these features and issues may, on the one hand, contribute to a better understanding legal proof, and, on the other hand, unearth features and issues so that they may then be subjected to more informed normative scrutiny. In discussing this methodological picture, I will defend some possible uses of "weird hypotheticals» ${ }^{32}$, and I will illustrate how this methodological approach can avoid the problem of «impossible epistemological demands» ${ }^{33}$.

Allen's primary targets in his critique of "weird hypotheticals» are the well-known Blue Bus and Gatecrasher examples and their variants ${ }^{34}$. These examples are typically invoked in both the evidence-law and philosophical literatures in the service of illustrating something problematic with statistical evidence. As Allen discusses, a «cottage industry» has arisen using the examples to distinguish statistical evidence from non-statistical evidence, attempting to explain exactly why the former is prob-

30 Allen \& Leiter, 2001: 1499. See also Goldman, 1999; Laudan, 2008.

31 Relative plausibility draws on insights from the philosophical literature on «inference to the best explanation». See Lipton, 2004; Harman, 1986. Because of the differing context and the complexities of legal proof, however, there are ways in which the inferential process differs from IBE as it is articulated in the philosophy of science and in epistemology. We discuss some of these differences in ALLEN \& Pardo, 2007. See also Pardo \& Allen, 2008: 243-47 (discussing why some of common objections to IBE in philosophy do not apply in the legal context).

32 Allen, 2020: 3.

33 Ibid.

34 In Blue Bus, the primary evidence linking the defendant company to a particular accident is evidence that the defendant owns a majority of the buses in the jurisdiction. The hypothetical is loosely based on dicta in Smith v. Rapid Transit, 58 N.E.2d 754, 755 (Mass. 1945). In Gatecrasher, the primary evidence against a particular defendant, alleged to have entered a ticketed event without paying, is evidence that a majority of attendees entered without paying. See CoHen, 1977: 75. 
lematic in a way that the latter is not ${ }^{35}$. He complains that the examples contribute "little of interest regarding the nature of juridical proof», do not attend to the "actual conditions of legal systems,» and «obscure rather than enlighten» ${ }^{36}$.

I agree that these examples are more misleading than helpful in understanding legal proof and that «the attention focused on these (and similar) hypotheticals may have simply impeded progress ${ }^{37}$. My diagnosis of the reasons why, however, differs in some respects from Allen's. In my view, there are two central problems with these examples ${ }^{38}$. The first problem, as Allen discusses, is that the question they are being used to answer is not a genuine problem for law in need of analysis or explanation ${ }^{39}$. In other words, I share with Allen the view that there is not a general problem in law involving «statistical evidence» ${ }^{40}$. Therefore, analyses or criteria that seek to explain a general, and meaningful, distinction between statistical and other evidence in law are doomed to fail (whether they rely on weird hypotheticals or not). Because the hypotheticals are being put in the service of answering an ill-formed question, it is not surprising that after decades of trying no one has successfully answered the question or «solved» the problem ${ }^{41}$.

The second problem is that, even if the question being addressed were genuine, the examples do not provide enough information to answer it. The hypotheticals are framed so as to imply that the evidence appears to be sufficient on its face to satisfy the applicable standard of proof ${ }^{42}$. Implicit in this framing, however, is the assumption that the standard of proof is a probabilistic threshold (say, 0.5 for the preponderance standard), which the statistic in the example surpasses. But this assumption is itself highly questionable ${ }^{43}$. If, instead, standards of proof are better understood as explanatory thresholds, as Allen and I argue, then the evidence is no longer necessarily sufficient on its face to meet the standard of proof ${ }^{44}$. Without more information,

35 Allen, 2020: 3.

36 Ibid.: 8, 10-11.

37 Ibid.: 5 .

38 These examples and these issues are discussed in more detail in PARDO, 2019.

39 See Allen 2020: 27-29 (discusses the uses of statistical evidence throughout the law).

40 PARDo, 2019: 265 («It is therefore a mistake to infer that the examples capture something essential about legal doctrine»). To be clear, the point is that there does not appear to be a general issue for statistical evidence as distinct from non-statistical or «individualized» evidence. Sometimes the former will be probative and sometimes not, and the same holds true for the latter. The quality, epistemic features, and probative value of legal evidence cut across the distinction between statistical and other evidence.

41 For further discussion, see PARDo, 2019: 253-66.

42 This apparent sufficiency then creates a puzzle for those who conclude that the evidence is insufficient. Ibid.

43 Ibid. Also problematic is the assumption that the statistic expresses the probative value of the evidence. Ibid.: 257-61.

44 Allen \& Pardo, 2019a: 6-15. 
we simply do not know what to infer about the evidence and its sufficiency ${ }^{45}$. Thus, the problems with these examples (and with analyses involving the examples) arise not because the hypotheticals are "weird» (although they are, for the reasons Allen discusses) - the problems arise because the hypotheticals are underdetermined and do not provide a clear answer to the question for which they are being invoked.

By contrast, I will discuss examples of «weird» hypotheticals that I think help to illustrate issues involving legal evidence and proof and that are consistent with the general methodological picture outlined above.

The first example is one that Allen critiques for making «impossible or outlandish epistemological demands» ${ }^{46}$. The example, presented as a critique of the importance of epistemic sensitivity for law, was designed to illustrate that even insensitive evidence may nevertheless be reliable and highly probative:

Drug Weight: A criminal defendant is tried for possessing a large amount of an illegal substance. According to the criminal statute at issue, the prosecution must prove that the defendant possessed 500 grams or more of the substance. A chemist who sampled and tested the substance will testify as an expert that the amount seized was over a kilogram. The expert is well qualified, employed an acceptable and reliable methodology, and otherwise satisfies the criteria for admitting expert testimony. The chemist's process, however, tends to overestimate weight by a very small amount (say, by one gram or less) ${ }^{47}$.

What exactly does this weird hypothetical help to illustrate? The evidence is highly probative in establishing the disputed fact of consequence-namely, that the amount seized was over 500 grams. Nevertheless, when we examine this evidence in terms of its apparent sensitivity (i.e., looking at the closest possibilities in which the disputed fact is false ${ }^{48}$ ), the evidence is insensitive because the expert's testimony may still report that the evidence meets the threshold even when it is slightly below the threshold. The point of the example, however, is that even if this were true, it does not and should not matter in cases such as the example because, given the large amount involved, the actual case is far away from that possibility. The key point is that the closest possibility in which a belief, verdict, etc. is false may not be a close

45 PARDO, 2019: 282 (arguing that the examples «remain underdetermined because of the nature of the standards [of proof] and the limited amount of information in the examples»).

46 Allen, 2020: 14 n. 48.

47 PARDO, 2018: 66.

48 Determining which alternative possibilities to consider can be a tricky issue in philosophical theorizing. One important difference between philosophy and law is that, consistent with relative plausibility, it is typically left to the parties to specify the alternative possible explanations that should be considered. Another important difference is that safety and sensitivity are «factive»—-they assume that the propositions at issue are true and compare those circumstances to circumstances in which the propositions are false. In law, the disputed propositions are typically not known to be true or false at the time of decision. Therefore, the relevant comparisons are: assuming the proposition is true, would the same decision follow if it were false (sensitivity) or how easily could the same decision follow if the fact were false (safety). 
possibility and thus may not have much of an effect of the probative value of evidence ${ }^{49}$. This conclusion follows from a general epistemological detail about sensitivity that, I argue, carries over to the context of legal evidence and proof. Because of this detail, whether evidence is sensitive or not does not tell us much about its probative value. By contrast, I argue, epistemic safety (or something like it) better tracks these considerations ${ }^{50}$. In the example, the testimony appears to be safe ${ }^{51}$ - even if there is a small range in which the expert's process is unreliable, the result here is so far outside of that range that the expert could not easily be mistaken about whether the amount exceeds 500 grams. Thus, epistemic safety may help to illustrate this feature of legal evidence $^{52}$.

What, then, is Allen's complaint about the hypothetical? In arguing that it makes impossible epistemological demands, he writes that:

If one «knows» that the process «overestimate[s] by a» gram, then one «knows» what the true amount is. If the chemist's mistake is within a range, then again you know the range of the true weight. This hypothetical makes sense only if you already know what you need to know, and if you do, then one simply presents it to the factfinder. If one does not «know» the error, then the argument about safety does not run through ${ }^{53}$.

But the hypothetical can work to illustrate its intended point without making impossible (or outlandish or peculiar) epistemological demands. We do not need to know the exact amount by which the process errs in a particular case-I agree that if we knew this, then we would know the true amount and could present this to the factfinder. Suppose that there is a small range in which the process is unreliable; sometimes the result is slightly over the true amount and sometimes it is slightly under, but (given our best available knowledge) the former tends to happen more often than the latter. Thus, if called upon to make a precise judgment in a particular case in which the true weigh was near the statutory threshold, then there is a real danger of a false positive (and false conviction) ${ }^{54}$. The idea of safety helps to illustrate this feature.

Moreover, Allen's own critique seems to draw on something like this epistemic consideration. He writes:

49 See Williamson, 2002: 159-60; Pardo, 2018: 66.

50 Ibid: : 69-74.

51 See also note 48.

52 This is not to suggest that safety captures all aspects of probative value; rather, it draws attention to an epistemic feature of the latter than may otherwise go unnoticed. For further discussion, see PARdo, 2018.

53 Allen, 2020: 15 n. 48.

54 As well as a false negative. Allen may object that, in the counterfactual, the factfinder should simply be presented with the fact that the particular testimony is within the range (and thus it would not be relied upon). Possibly_ but such an argument seems to rely on the sort of a priori assumption that Allen rejects. By contrast, a naturalized approach that pays close attention to the actual conditions of the legal system suggests that reliance on and deference to prosecution experts, even when their testimony exceeds the limits of known reliability, is a problem in criminal cases. National Research Council, 2009. 
The fact that the Blue Bus Company owns $70 \%$ of the buses does not entail that there is a $70 \%$ chance that the Blue Bus Company caused the harm in question. The Blue Bus Company may own $70 \%$ of the buses but have extremely effective safety measures in place; they may have well-seasoned drivers with impeccable driving records; they may not even have buses that frequently visit the location of the harm at the time in question. Actual factfinders could easily regard this statistic as being insufficient to ground liability because these relevant possibilities remain unaccounted for by the statistic about ownership ${ }^{55}$.

Indeed, this is exactly right. These «unaccounted for» «relevant possibilities» could easily be the case (i.e., the situation is unsafe) and this, in turn, diminishes the probative value of the evidence ${ }^{56}$. When the alternative possibilities could not easily be the case, then the evidence will have higher probative value in proving the disputed fact. Nothing in my previous analysis, or in this discussion, is meant to suggest that safety is the «key» to probative value or the only relevant concept for understanding legal evidence. Rather, it provides one more analytical tool for understanding and making explicit features of legal evidence, or the process of legal proof, that are implicit and may otherwise go unnoticed ${ }^{57}$. And it is possible to use this tool without making impossible epistemological demands.

My second, and final, example concerns Gettier-type cases and their potential relevance to legal proof. Within epistemology, this particular sub-genre is probably the best example of "weird hypotheticals» that seem far removed from the practical realities of legal proof ${ }^{58}$. As I have argued, however, even Gettier cases contain potential insights for law and help to unearth unnoticed features of legal evidence and proof ${ }^{59}$. Within epistemology, the examples are typically used to illustrate that even true and epistemically justified beliefs may fall short of qualifying as «knowledge» because of an accidental or coincidental relationship between the belief's truth and the justifying evidence. A similar problematic gap between evidence and truth may arise in the context of legal verdicts. Here is a «weird hypotheticals» that illustrates such a gap:

Framed Defendant: The police arrest a motorist and plant drugs in his car. He is convicted at trial of illegal possession based solely on testimony from the arresting officers and the planted drugs. As it turns out, the defendant did have illegal drugs in his car at the time that never were discovered. The verdict that the defendant possessed drugs is therefore both true and justified (that is, the evidence at the time of the trial is sufficient to establish a conviction beyond a reasonable doubt), but the truth and the justifying evidence are disconnected. The truth of the verdict is purely coincidental or accidental ${ }^{60}$.

55 Allen, 2020: 17-18.

56 See note 48 .

57 Allen likely agrees with this methodological point. See ibid.: 20 (distinguishing the «many tools to use in thinking about evidence» from «efforts to find the solution or key» to legal proof). This is why I noted above, see note 29 , that the differences between our methodological pictures are likely more a difference in focus and framing rather than substantive disagreement.

58 Gettier, 1963. See also Lycan, 2006 («The Gettier problem became a leading focus, if not the focus, of disenchantment with the definition-and-counterexample method of analytic philosophy»).

59 PARDo, 2010.

60 Ibid.: 57. 
My view is that such a gap is a problem that renders the verdict an error in need of correction ${ }^{61}$. Moreover, the hypothetical helps to illustrate a genuine epistemological issue that may arise for courts. One context in which it may arise is when criminal defendants seek a new trial based on newly discovered evidence. The prosecution may respond to such claims by pointing to other evidence of guilt that was not presented at the trial and that purports to show the defendant's guilt ${ }^{62}$. This then raises a question for courts reviewing the issue: must the evidence that purports to establish guilt have been «internal» to the trial and presented to the factfinder? In Reese, for example, the court answered this question in the affirmative-concluding that the prosecution must present any additional incriminating evidence in a new trial ${ }^{63}$.

To be clear, nothing in the "weird hypotheticals» necessarily tells us how the law ought to respond in such situations ${ }^{64}$. At the very least, however, the hypotheticals help to reveal epistemic issues that may arise in the context of legal proof. Once the issues are made explicit ${ }^{65}$, there is then space for a more informed debate about how the law does, or ought, to proceed (as opposed to leaving the issue implicit and possibly to the whims of individual decision-makers).

\section{CONCLUSION}

The methodological picture I have described is one way in which epistemology may contribute to the law of evidence. It is intended to be an optimistic one and an invitation to epistemologists. For anyone taking up this invitation, I think there are three important points that Allen's critique reveals. First, it is important (and sometimes difficult) to accurately describe the underlying legal details. Second, there is a complex relationship between epistemology and law. It is unlikely that useful connections will involve a simple application of some epistemic concept or issue

61 See ibid. This problem arises even when the gap does not arise because of government misconduct. See ibid.: at 51-52 (presenting additional examples).

62 See, e.g., Pennsylvania v. Reese, 663 A.2d 206 (1995).

63 Ibid:: 210 («Because the jury did not hear evidence of other explanations [...], it would have been improper for the [reviewing] court to have considered it»).

64 In addition, nothing in the methodological picture that I have presented relies on privileging «intuitions» about the hypotheticals. See Allen, 2020: 5 (critiquing reliance on intuitions about the cases). The role of intuitions in epistemology is a controversial topic. See Goldman, 2012; Cappelen, 2012. In my view, this issue need not be resolved for epistemology to contribute to legal proof.

65 Because, under my methodological picture, epistemology can contribute by unearthing epistemic issues implicit in law, it is not a criticism of this picture that the law does not explicitly refer to the epistemic concepts. See Allen, 2020: 31 n. 94. Moreover, given the complex relationship between epistemology and law, the latter may be useful to law even when a concept or issue differs between the two contexts. For example, aspects of «knowledge» may be useful for understanding law, even when legal verdicts fail to qualify as «knowledge», according to philosophical analyses. See PARDO, 2010: 5455. See also PARDo, 2018 (arguing that safety illuminates aspects of legal evidence regardless of whether it is a necessary condition for knowledge); Moss, 2021. 
to law-a particular concept or issue may have different features, or play different roles, in the legal context than it does in other epistemological contexts. Third, it is probably time to stop trying to «solve» issues related to the Blue Bus and Gatecrasher hypotheticals and, for those interested in contributing to our understanding of the law of evidence, to focus elsewhere ${ }^{66}$.

\section{BIBLIOGRAPHY}

Allen, R.J. \& B. Leiter, 2001: «Naturalized Epistemology and the Law of Evidence», in Virginia Law Review, 87(8): 1491-1550.

Allen, R.J. \& M.S. PARdo, 2007: «Probability, Explanation, and Inference: A Reply», in The International Journal of Evidence \& Proof, 11: 307.

— 2019a: «Relative Plausibility and Its Critics», in The International Journal of Evidence \& Proof, 23(12): $5-58$

— 2019b: «Clarifying Relative Plausibility: A Rejoinder», in The International Journal of Evidence \& Proof, 23(1-2): 2-5-17.

Allen, R.J., 2020: «Naturalized Epistemology and the Law of Evidence Revisited», in this journal.

Cappelen, H., 2012: Philosophy without Intuitions, Oxford: Oxford University Press

Conen, L.J., 1977: The Probable and the Provable, Oxford: Oxford University Press.

Enoch, D., Spectre, L. and Fisher, T., 2012: «Statistical Evidence, Sensitivity, and the Legal Value of Knowledge», in Philosophy \& Public Affairs, 40(3): 197-224.

Gettier, E., 1963: «Is Justified Ture Belief Knowledge?», in Analysis 23: 121.

Goldman, A.I., 1999: Knowledge in a Social World, Oxford: Oxford University Press.

— 2002: "Quasi-Objective Bayesianism and Legal Evidence», in Jurimetrics, 42: 237.

- 2012: «Philosophical Naturalism and Intuitional Methodology», in Goldman, A.I. (ed.), Reliabilism and Contemporary Epistemology. Oxford: Oxford University Press.

HaAcK, S., 2014: Evidence Matters: Science, Proof, and Truth in the Law, Cambridge: Cambridge University Press.

Harman, G., 1986: Change in View: Principles of Reasoning, Cambridge, MA: MIT Press.

Kornblith, H., 1994: «What is Naturalistic Epistemology?», in Kornblith, H. (ed.), Naturalizing Epistemology, Cambridge, MA: MIT Press.

Laudan, L., 2008: Truth, Error, and Criminal Law: An Essay in Legal Epistemology, Cambridge: Cambridge University Press.

Leiter, B., 2017: «Naturalism in Legal Philosophy», in Zalta, E. N. (ed.), Stanford Encyclopedia of Philosophy, available at: https://plato.stanford.edu/entries/lawphil-naturalism/.

Lipton, P., 2004: Inference to the Best Explanation. London: Routledge.

LyCan W.G., 2006: «On the Gettier Problem Problem», in Epistemology Futures, Oxford: Oxford University Press

Moss, S., 2021: «Knowledge and Legal Proof» in Oxford Studies in Epistemology Vol. 7, Oxford: Oxford University Press.

National Research Council, 2009: Strengthening Forensic Science in the United States: A Path Forward, Washington D.C: The National Academies Press.

Quine, W.V., 1969: «Epistemology Naturalized», in Ontological Relativity and Other Essays, New York:Columbia University Press.

66 Possible epistemic issues include those involving testimony, epistemic injustice, experts, deference, disagreement, group agency and collective judgments, and specific issues involving the inferences and reasoning in particular types of legal cases, among many others. 
Pardo, M.S., 2007: «Testimony», in Tulane Law Review, 82: 119.

- 2010: "The Gettier Problem and Legal Proof», in Legal Theory, 16: 37.

— 2018: "Safety vs. Sensitivity: Possible Worlds and the Law of Evidence», in Legal Theory, 24(1): $50-75$.

— 2019: "The Paradoxes of Legal Proof: A Critical Guide», in Boston University Law Review, 99: 233.

Pardo, M.S. and Allen, R.J., 2008: "Juridical Proof and the Best Explanation», in Law \& Philosophy, 27(3): 223-68.

PArk, R.C., 2001: "Grand Perspectives on Evidence Law», in Virginia Law Review, 87: 2067.

Smith, M., 2018: "When Does Evidence Suffice for Conviction?», in Mind, 127(508): 1193-1218.

Williamson, T., 2002: Knowledge and its Limits, Oxford: Oxford University Press. 
